\title{
Analysis and Countermeasure of VOCs Source in Automobile Production Process in China
}

\author{
Tingting Cheng ${ }^{1}$, Jun Chen ${ }^{1}$, Ke Wu ${ }^{1 *}$, Jianguo Liu ${ }^{2}$, Siheng Lu${ }^{1}$, Shouchuang Hu${ }^{1}$ \\ 1 - Department of Biological and Environmental Engineering, Hefei University; Collaborative Invention Center \\ for Environmental Pollution Precaution And Restoration of Anhui, Hefei 230601, P. R. China. \\ 2 - Hefei Institutes of Physical Science, Chinese Academy of Sciences, Hefei 230031, P. R. China \\ Address: No. 99, Jinxiu Road, Hefei 230601, P. R. China. *Corresponding author.e-mail: wuke@hfuu.edu.cn
}

\begin{abstract}
This article describes the hazards and causes of VOCs as well as the state of VOCs. It is the main culprit in the production of VOCs, which is the main culprit of the production of VOCs source materials in automobile, and analyzes the production of VOCs in the raw material production process from the source. Finally, proposed reduction measures from three aspects of the raw materials, production, management.
\end{abstract}

Keywords: VOCs, coatings, adhesives, plastic parts, rubber parts.

\section{INTRODUCTION}

Recently, The air pollution situation is becoming increasingly serious in China, volatile organic compounds (VOCs) emissions seriously affected the ambient air quality. Volatile Organic Compounds (VOCs) refer to the general term of a class of organic compounds with high vapor pressure and volatile at room temperature and atmospheric pressure [1], including various combinations of alkenes, olefins, Oxygen and halogenated hydrocarbons, such as "Three benzene", formaldehyde and ethyl acetate [2]. Studies have shown that VOCs are $\mathrm{O}_{3}$ and PM2.5 form one of the important precursor materials [3], VOCs can react with the atmosphere NOX in the ultraviolet radiation, produce ozone and other secondary pollutants, which resulting in photochemical pollution [4]. At the same time, VOCs also have an impact on human health, of which n-hexane, heptane and octane will affect the human central nervous system [5]; polycyclic aromatic hydrocarbons and many chlorine-containing organic due tocarcinogenic, teratogenic and mutagenicity. Long-term exposure to high concentrations of VOCs can cause headaches, nausea, vomiting, coma and other symptoms, and damage the liver, kidney, brain and other vital organs [6]-[8]. All in all, VOCs are one of the key pollutants that endanger the atmospheric environment and human health, and it is imperative to control VOCs emissions.

According to the results of 2015 national human source results listing the emissions of volatile organic compounds, that the main sources of industrial sources are traffic, the source of life, agricultural sources in artificial source VOCs emissions constitute [9]. At present, China's annual emissions of anthropogenic
VOCs has been as high as 30 million tons. Among them, the industrial source emissions accounted for the proportion of the entire human source of $55.5 \%$, is the most important source of emissions [10]. At the same time, on July 8, 2016, the Ministry of Industry and the Ministry of Industry organized the " Action Plan for Volatile Organic Compounds in Key Industries " indicated that, industry is a priority area for VOC emissions is the focus of industrial areas to reduce VOCs with emissions accounting for more than $50 \%$ of total emissions, Complex, with high strength, high concentration and many other types of pollutants, recycling difficult with high cost. At present, the air pollution control situation is grim.It is of great significance to accelerate the key industry VOC reduction to promote industrial green development and promote the improvement of atmospheric environment quality and keep human health.

The production of volatile organic compounds is more complex in the process of automobile production, resulting in hundreds of VOCs, including hydrocarbons, aldehydes, ketones and so on. The resulting VOCs are directly related to the types of parts used in the production of automobiles and the accessories of the automobile manufacture process. The influence of the VOCs is automotive coatings, adhesives, plastic parts and rubber parts and so on. 


\section{ANALYSIS OF VOCS SOURCE MATERIAL IN AUTOMOBILE PRODUCTION PROCESS}

Coatings

In the developed countries of the automobile industry, the amount of paint used in the paint production occupies an extremely important place [11]. Coatings produce large amounts of malodorous and VOCs in transporting and using processes because of the large amount of organic solvents in the production. Therefore, the paint industry is an important industrial source of atmospheric VOCs [12].

Paint is mainly composed of film-forming materials, pigments, organic solvents, additives [13]. The main components of film-forming substances include acidic phenolic resin, phenolic resin, ureaformaldehyde resin, etc., these organic compounds in the process can be used to release benzene, methanol, chlorinated ethylene, hydrogen chloride and phenols and other toxic and harmful gases [14]. Most of these related solvents are strong organic solvents, commonly used solvents include alcohols, esters, ethers, ketones, aliphatic hydrocarbons and chlorine-containing organic matter. In principle, these solvents are not part of the coating and not present in the coating but acting primarily to dissolve the film-forming material used in the coating in a liquid environment to facilitate application and to form a solid coating, After the formation of the volatile to the atmosphere. So the main source of pollution in the paint production process is the solvent [14].

A total of fifteen major VOCs were detected in the automotive coating production workshop, including benzene, toluene, ethylbenzene, xylene, ethyl acetate, butyl acetate, methyl isobutyl ketone, propylene glycol methyl ether acetate and Diol butyl ether and so on, the concentration of detection range of $0.51 \sim 593.14 \mathrm{mg} /$ $\mathrm{m}^{3}$. The concentration of TVOCs in the production stations was significantly different, and the concentration of VOCs in the gas samples of different batches in the same production chain was different. Xylene and butyl acetate are the main VOCs for the production of indoor air [15].

Adhesive

Automotive adhesives in the application of the car is very wide, Coverage is about $20 \mathrm{~kg}$ per car. The application of coating technology in automobile manufacturing can enhance the structure of automobile structure, heat and vibration, but also can replace some parts of the welding, riveting and other traditional crafts, simplify the production process, optimize the product structure [16], with The use of the automotive industry towards energy-saving lightweight, highspeed environmental protection, comfort and safety, low-cost trends, glue and related materials in the automotive manufacturing will become more prominent and key.

The volatile organic compounds (methanol, acetone, methyl acetate, tert-butanol, vinyl acetate, ethyl acetate) in the adhesive were analyzed. The linear range of the six volatile organic compounds was methanol $40 \sim 400 \mathrm{ug} / \mathrm{g}$, acetone 4 to $40 \mathrm{ug} / \mathrm{g}$, methyl acetate 9.2 to $92 \mathrm{ug} / \mathrm{g}$, t-butanol 3.2 to $32 \mathrm{ug} / \mathrm{g}$, vinyl acetate 7.5 to $75 \mathrm{ug} / \mathrm{g}$, and ethyl acetate 4.5 to $45 \mathrm{ug} /$ $\mathrm{g}$ [17]. At the same time, the results show that the main components of the welding glue are butyl rubber, processed oil and carbon black, and the influence of the three on the content of VOC is the processing oil > carbon black > butyl rubber; the main component of the coating is (PVC) resin, DOP (dioctyl phthalate) plasticizer and organic solvent, which has a great impact on the emission of automotive VOCs. The main components of the total glue are isocyanate, polyether polyol And so on, its ethylbenzene content is relatively high and have great impact on vehicle VOCs emissions [18].

\section{Plastic parts}

With the progress of science and technology, the status of plastic parts in automobile production is more and more important, and its effect on improving vehicle performance, appearance and light weight is obvious [19]. The results show that the vehicle quality can be reduced by $10 \%$, the fuel consumption can be reduced by $6 \% \sim 8 \%$, the fuel efficiency is improved by $5.5 \%$ and the emission is reduced by $5 \% \sim 6 \%$; the vehicle mass is reduced by $100 \mathrm{~kg}$ [20]. October 2016, China Automotive Engineering Society released "energy and new energy vehicle technology road map." The road map pointed out that by 2020, 2025, 2030, the vehicle quality than in 2015 were $10 \%$, $20 \%, 35 \%$. At present, the average use of bicycle bicycles in developed countries is more than $150 \mathrm{~kg}$, accounting for $12 \%$ to $20 \%$ of the total weight of the car, while the use of bicycles in China accounts for about $7 \%$ to $10 \%$ of the weight of vehicles [21]. Thus, the application of automotive plastic parts will be more and more widely. Over the past 30 years, the amount of plastic used in automobiles has risen from about 10 $\mathrm{kg}$ in the early $1960 \mathrm{~s}$ to $200 \mathrm{~kg}$ at the beginning of the 21 st century. At present, the application of plastic in the car is divided into three categories: external parts, interior parts and functional structural parts [22], including automotive dashboard, car handrails, handles, liner, car bumpers and so on.

The main components of automotive plastics are polypropylene (PP), ABS, polycarbonate (PC), polyethylene $(\mathrm{PE})$, polyurethane $(\mathrm{PU})$ and polyvinyl chloride (PVC) [23]. Polypropylene plastic in automotive plastic parts of the most widely used, polypropylene (PP) with good mechanical properties, low relative density, easy processing and other excellent characteristics. Because of its excellent heat resistance, it is widely used in automobile production, but PP materials in the production and use of the process will inevitably produce some monomer, oligomers and other pollutants [24]. A total of 28 components were detected in their volatile gases, including alkanes, aldoxones, alkoxides and olefins, 
with acetone $(14.12 \%)$ and 2, 4 - dimethylheptane $(12.97 \%)$ of the most [25].

\section{Rubber products}

Rubber products in the use of automotive production accounted for about $5 \%$ of the weight of the vehicle, the amount can not be underestimated. In addition to the main components of rubber tires, there are also rubber seal products, rubber shock products, hoses, tape and other rubber products in the car.

Rubber products used in the production of raw materials are mainly raw rubber with agents and as a skeleton material of fiber and metal materials. Raw rubber includes natural rubber and synthetic rubber (silicone rubber, styrene-butadiene rubber, cis-methyl rubber, isoprene rubber, etc.) [26]. The compounding agent is an auxiliary material added to improve the properties of the rubber, according to the function can be divided into curing agent, curing accelerator, antiaging agent, anti-scorching agent, plasticizer, with thousands of complex ingredients, complex composition. These materials are masticated (according to different types of raw rubber, the temperature is usually $30-40{ }^{\circ} \mathrm{C}$ ), kneaded (temperature $80-160{ }^{\circ} \mathrm{C}$ or so), rolled out pressure, petaled, molded and other processes finally got rubber products. In this process, due to high temperature and high pressure, they will make the organic ingredients in the volatile or cracked and resulting in a large number of odor VOCs exhaust. VOCs waste gas in the mixing, pressing, rolling, curing and other processes is accounted for about $20 \%$ of the total emissions of rubber products production processwith high temperature and complex composition, low concentration characteristics, which composed mainly by carbon disulfide, Carbon, hexane, toluene, hydroquinone and other components [27]. According to the American Rubber Manufacturers' Association, the emission of VOCs in the production process of rubber products is the largest, and the pollutants emitted by the vulcanization process include toluene, $\mathrm{m}$-xylene, p-xylene and carbon disulfide. Other processes are mainly polluted it is carbon disulfide, carbon tetrachloride and hexane [28].

\section{REDUCTION MEASURES}

In the context of environmental protection, automobile manufacturing industry as a labor and knowledge-intensive industries, reducing the production of atmospheric environmental pollution has became the industrial development needs to bear the important social responsibility. Automotive production industry VOCs cut not only in the production process to optimize the production process, but also from the source of VOCs - the production of raw materials, choose clean green materials for the automotive production process to contribute to control VOCs emissions. In this regard, the car companies and the relevant departments can make some improvements:
Both government and enterprises should strengthen VOC emissions management. Government departments should strengthen the emission requirements of industrial production, improve the laws and regulations to restrict emissions of production enterprises. Enterprises should not only strengthen the managemental requirements of emission of pollutants in the producing process and establish strict policies but also increase the VOCs post-treatment facilities that can burn or wash waste gases and then emit them. There is a remarkable example of RTO device in Hefei Economic Development Zone. One of car manufacturing plant use the RTO device to burn the organic waste gases emitted from the spray room, natural drying room and industrial drying room. A large amount of organic waste gases produced in the coating process are oxidized and decomposed in the case of natural gas combustion and becomes non-toxic $\mathrm{CO}_{2}$ and $\mathrm{H}_{2} \mathrm{O}$. The heat of the oxidized high-temperature gas is "stored" by the ceramic generator for preheating the new organic waste gas and saving the fuel consumption required for the temperature rise. The purification efficiency is generally greater than $98 \%$.

In order to take the road of cleaner production, enterprises have to choose new technologies, new materials and new technology. They should initiate environmental protection activities from the source to the process, every step of the production. They should better control the amount of pollutants from the resource and pay attention to the process and process transformation and select the optimal coating ratio and spraying process to reduce the use of related raw materials and emissions. In addition, they ought to use green production materials and select coatings and adhesives of aqueous solvent type to reduce the VOCs emissions from organic solvents. In term of automotive plastic parts, they should utilise long-chain polymer materials to reduce the plastic parts pyrolyzed in high temperature environment and producing VOCs gas.

Enterprises must speed up the improvement of the existing process, controlling the amount of pollutants from the parts and assembly process to the use of source materials. They should pay attention to the process and process transformation and select the optimal coating ratio and spraying process to reduce the relevant use of raw materials and emissions. For example, After a car manufacturing plant Hefei Economic Development Zone take the lead in the use of environmentally friendly water-based paint, the third factory has adopted the most environmentally friendly water-based B1B2-free coating process, which is the shortest spray process today. Through the optimization of coating, theseenterprises have reserved the anti-UV and anti-stone attack function of floating coat, which not only can subtract the equipment caused by the equipment investment and energy costs, but also make a significant reduction in VOC pollution to the 
environment. It is reported that the use of water-based B1B2 exemption technology not only can save $25 \%$ to $30 \%$ of the energy and reduce $15 \%$ to $20 \%$ of the $\mathrm{CO}_{2}$, $20 \%$ to $25 \%$ of the waste, but also reduce the consumption of coating about $2 \mathrm{~kg}$ per car. The enterprise has adopted green technology to reduce the pollution emissions to the minimum.

\section{ACKNOWLEDGMENTS}

This research was supported by Municipal Solid Waste Disposal Innovation Team of Anhui Province ([2015]49), Collaborative Innovation Center for Environmental Pollution Control and Ecological Restoration of Anhui Province ([2014]28), Major Scientific and Technological Projects of Anhui Province (16030801119).

\section{REFERENCE}

11] Wang H.L., Zhang G.N., Nie L., et al. Control and management of industrial VOCs in China. Environmental Science 32. 2011, pp. 3462-3468. (in Chinese)

[2] Hunter P, Oyama S T. Control of volatile organic compound emissions: conventional and emerging. New York: John Wiley \& Sons, Inc., 2000.

[3] Song Y., et al. Characteristics of Fine Particles in Beijing. Environmental Science 2002, pp. 11-16. (in Chinese)

[4] Shi Y.Z. Simulation of Photochemical Smog in Suburbs of Beijing City. Journal of climate and environmental research 2008, pp. 84-92. (in Chinese)

[5] Zhang C.N., Ye D.Q., Wu J.L. Adsorption and Catalytic Purification Technology of Advanced and Practical Volatile Organic Waste Gas. Energy Environmental Protection 2005, pp. 5-8. (in Chinese)

[6] Zhou J,You Y, Bai Z P, et al. Health risk assessment of personal inhalation exposure to volatile organic compounds in Tianjin, China. Science of the Total Environment 409.2011, pp. $452-459$

[7] Shirasu M, Touhara K. The scent of disease: volatile organic compounds of the human body related to disease and disorder.The Journal of Biochemistry, 150. 2011, pp. 257-2.

[8] Rudnicka J, Kowal kowski T, Ligor T, et al. Determination of volatile organic compounds as biomarkers of lung cancer by SPME-GC-TOF / MS and chemometrics. Journal of Chromatography B: Biomedical Sciences and Applications 879. 2011, pp. 3360-3366

[9] Ning M., Sun Y.M.Thanks and Approaches to the Prevention and Control of Volatile Organic Compounds in the 13th FiveYear Plan. World Environment 2016, pp. 27-29. (in Chinese)

[10] Anonymous. About the cutting action plan for key industries volatile organic compounds (2016-2018) interpretation of the. Chinese tyres resources comprehensive utilization 2016, pp. 23-24. (in Chinese)

[11] Zhang W.Y., Hou S.Z. Development and Application of
Automotive Coatings. Modern Coatings and Coatings 16. 2013, pp. 23-25. (in Chinese)

[12] Chen Y., Ye D.Q., Liu X.Z., et al.Study on source tracking and industry characteristics of VOC emission from industrial sources in China. China Environmental Science 32. 2012, pp. 48-55. (in Chinese)

[13] Liu H., Hu W.Q. Production and application of iron white powder. Science and Technology Press, 1992. (in Chinese)

[14] Lin H. Synthesis and Technology of Acrylic Resin in Clean Production of UV Coatings. Hunan University, 2007. (in Chinese)

[15] Zeng P.Y., Li J.J., Liao D.Q., et al. Emission characteristics and safety evaluation of VOCs in the production of automotive coatings // The 16th National Symposium on Environmental Microbiology. 2013, pp. 4592-459. (in Chinese)

[16] Shen F., Chen Y., Wu S.Z. Introduction of Automotive Adhesive and Sealant // 2004 Beijing International Adhesive Technology Seminar. pp. 608-617. (in Chinese)

[17] Zhang Y.M., Zha L., Fang J.L., et al. Determination of Volatile Organic Compounds in Tobacco Adhesives by HeadspaceGas Chromatography. Fine Chemical Industry 29. 2012, pp. 717-720. (in Chinese)

[18] Xu S.Y., Jin Y.M., LI L., et al. Effects of vehicle adhesives on air quality in the vehicle. China Adhesives 2013 pp. 14-17. (in Chinese)

[19] An S.X. Analysis of automotive plastic materials application and development trend. Urban construction theory: electronic version, 2013, pp. 132-133. (in Chinese)

[20] Liu J.C., Cao D., Li J., et al. Application of Plastic Composites in Automobile Lightweight. Modern Parts and Components, 2013, pp. 39-42. (in Chinese)

[21] Yang T. Application and prospect of plastic material application in automobile industry. New Materials for Chemical Industry, 2013, pp. 1-4. (in Chinese)

[22] Cao J.Y. Application of plastic material in automobile interior and exterior decoration. Heilongjiang Science and Technology, 2016, pp. 13.(in Chinese)

[23] Yang Z.M. Automotive waste plastics and its recycling / / National Plastics modification and alloy industry technology exchange annual meeting. 2006. (in Chinese)

[24] Huang J.B., Li J.J., Yang B., et al. Preparation of Low TVOC Polypropylene Materials for Vehicles. Plastics Industry 39. 2011, pp. 113-115. (in Chinese)

[25] Cui W., Tao R., Li R.H. Study on Volatile Gas Produced by Polypropylene by Solid Phase Microextraction and Chromatography-Mass Spectrometry. Plastics 39. 2010, pp. 139-141. (in Chinese)

[26] Zeng W.Y. Source and purification technology of organic waste gas in heavy polluting industry. Zhejiang University, 2014. (in Chinese)

27] Fang M.Q., Huang Y., Liu Z.Z., et al. Ozone Oxidation Chemical Absorption Research Safety and Environmental Engineering 17. 2010, pp. 23-25. (in Chinese)

[28] Zhang Z.L. Emission coefficient of organic waste gas in the production of rubber products. Rubber Industry 53. 2006, pp. 682-683. (in Chinese) 